The Third Pole: Journal of Geography

Vol. 18 - 19: 45-54, 2019

DOI: https://doi.org/10.3126/ttp.v18i0.27994

Department of Geography Education,

Central Department of Education, T.U., Kathmandu, Nepal

\title{
LINGUISTIC GEOGRAPHY OF NEPALESE LANGUAGES
}

\section{Rajendra Khanal, $\mathbf{P h D}^{1}$}

\begin{abstract}
The main aim of this paper is to present the linguistic geography of Nepalese languages with a brief introduction to linguistic geography using secondary sources of data. The study is focused to identify and analyze the diversity within a language. Different tables are prepared to determine a common ground in geographical bases to study language in geographical, social, cultural and historical relativity. A wide range of diversities found in major languages that spoken in Nepal i.e. Newar, Magar, Rai, Tharu and Nepali. The findings indicate that linguistic variables are formed out of the geographical diversity. All languages of Nepal have their own geography and cultural background.
\end{abstract}

Key words: Linguistic geography, linguistic transition, dialects, linguistic diversity, linguistic continuity.

\section{Introduction}

Nepal is multi-cultural and multi-lingual country, at present a total of 123 different languages are spoken in the country (CBS, 2014). The languages that spoken in Nepal can be classified into four broad language family groups as Indo-Aryan, Tibeto-Burman, Munda and Dravidian; which are not uniformly distributed over the country. Nepal is the meeting ground of the northern Lamaism and southern Brahmanism and undertakes broad cultural areas taking linguistic unit as their core region (Gurung, 1989). Gurung further stated that the people of the northern valleys follow Tibetan cultural tradition in language, religion and economy, while the people of the Tarai are oriented towards the culture and economy of the Gangetic plain. Between these two peripheral cultural areas lies the tribal and Pahari cultural areas arranged in successive ecological zones.

The spoken language of any community is considered as the identity of its culture. What they say, how they speak, and how they conversation are considered extraordinarily

1 Dr. Khanal is a Lecturer, Department of Nepali Education, Central Department of Education, Tribhuvan University 
powerful of their identity as language. Thus, language is a system of communication that persons within a community use to convey ideas and emotions and the study of languages is called linguistics. Likewise, people who communicate easily speak a very similar version of a language, known as a dialect. In this context, every community living in Nepal has a language of mother tongue. But the same ethnic community people have used different languages when the separation of their settlement and geography. This variation emerged as the study of linguistic geography. Thus, linguistic geography is an emerging field of research in many disciplines like science, arts and humanity. However, its development is still in a primary stage. Only small number of academicians have involved in the study of linguistic geography. The credit goes to the Tiwari (2005) an Indian linguist who has first attempted to the notion of linguistic geography in this continent.

Linguistic geography used to analyze linguistic community and variables of dialects and sub-dialects of a particular language (Tiwari, 2005; Omar \& Alotaibi, 2017) by considering certain geographical area is spoken of languages and dialects compare and contrast the characteristics; and comprehensibility of the dialects and sub-dialects of each language using its isoglosses. Because of isoglosses are supposed to the glosses for distinguishing languages and their dialects. The geographical territory covered by a language as linguistic geography can be used for used the comparative historical method for the study of linguistic geography. Tiwari (2005) identified the variety of regional distribution of linguistic diversity in Northern India and their limitations of Indo-Aryan language family groups regarding languages and dialects on the basis of sounds, lexemes, meaning, patterns, and sentences.

It is difficult to identify the exact features of linguistic geography in Nepal due to strong effects of socio-cultural aspects on spoken languages of the communities. Their sociocultural values and norms, and political situation determine local identity, structure and relations to the languages. For example, Tharu, Rai, Limbu etc. people have mostly spoken in their own languages and dialects based on their socio-cultural norms while Nepali (Indo-Aryan) language as the lingua franca of the country (Gurung, 1989).It shows that the people who speak the same language often reside in a community and regulate their own code of conduct through language. In addition, the minority people who share the same place unanimously, although dominated by the dialectics of the continuum. Therefore, it is not possible to do the objective analysis from linguistic geography, and it thus, is of relative sense. The access of communication normally creates spatial diversity of languages such as face to face contact or interpersonal communication, and transmission of information through technological device of the mass media (Gold, 1980). 
Linguistic geography is a study of the diversities in a language (Tiwari, 2005; Omar \& Alotaibi, 2017; Dhungel, 2008; Neupane et.al, 2013). The findings of numerous studies indicate that geographical locations and their regional distributions are associated with the diversity of cultures and spoken languages. However, there is still unraveling questions to address the answer to how the same communities used different words for the same phenomena in different locations? For example, Guava is known as Belauti in the western parts of Nepal, while Aamba in the eastern part. Dhungel (2008) analyzed the situations of subjective and objective cases, use of $/ \mathrm{n} /$ instead of [ən], use of $/ \mathrm{d} /$ instead of [dh], 'Rhachhen' as 'Raan' and so on out of the observation. It shows the pronunciations are, varied from one place to another and make linguistic geography. In this context, this paper is to seek the spatial variations of languages and linguistics in different geographical locations of Nepal i.e. eastern, central, western and so on. Similarly, pumpkin a name of a vegetable is also known as 'Pharsi' in one place while "Kabeli" in the other. There are so many words can be variously used in different parts of Nepal, such as, Goda and Khutta, Tyhin and Tetna, Gedo and Bedulo. All these terms and terminology and their pronunciations vary from one place to another can be taken examples linguistic geography.

\section{Methods and Materials}

This paper is mainly based on the narrative research framework and secondary sources of data. Data were collected from reviews of various books, journals, the Internet and related archival documents. However, the publication of Central Bureau of Statistics (CBS) was the main source of data regarding the spatial distribution of languages and linguistics in Nepal. Analytical and descriptive methods are used for data analysis.

\section{Result and Discussion}

Language and linguistic situation in Nepal: The Nepalese society has characterized to socio-cultural diversity and a land of transition between the northern highland and southern lowland as well as the occidental Khas and oriental Kirant (Gurung, 1989). Racially, the people inhabiting Nepal were drawn from two stocks: Mongoloids (Kirants) from the north and east, and Caucasoid (Khas) from the west and south. These stocks are divided into different caste and ethnic groups which formed the spatial aspects of linguistic geography. It is argued that natural and economic diversity among regions was an asset in maintaining circulation within varied territorial parts of the country. In contrast, social diversity is represented by race, language, and culture and tends to break communication. 
Table 1: Languages and Number of speakers in Nepal

\begin{tabular}{|c|c|c|c|c|c|}
\hline Language & Number & \begin{tabular}{|l|} 
Percentage \\
\end{tabular} & Language & Number & Percentage \\
\hline \multicolumn{6}{|c|}{ 1. Indo-Aryan } \\
\hline Nepali & $11,826,953$ & 44.64 & Maithili & $3,092,530$ & 11.67 \\
\hline Bhojpuri & $1,584,958$ & 5.98 & Tharu & $1,529,875$ & 5.77 \\
\hline Bajjika & 793,416 & 2.99 & Baitadeli & 272,524 & 1.03 \\
\hline Dotyali & 787,827 & 2.97 & Aachami & 142,787 & 0.54 \\
\hline Urdu & 691,546 & 2.61 & Rajbanshi & 122,214 & 0.46 \\
\hline Awadhi & 501,752 & 1.89 & Hindi & 77,569 & 0.29 \\
\hline Magahi & 35,614 & 0.13 & Bajhangi & 67,581 & 0.26 \\
\hline Rajasthani & 25,394 & 0.10 & Maghi & 24,422 & 0.09 \\
\hline Bengali & 21,061 & 0.08 & Tajpuriya & 18,811 & 0.07 \\
\hline Angika & 18,555 & 0.07 & Darchuleli & 5,928 & 0.02 \\
\hline Kumal & 12,222 & 0.05 & Dailekhi & 3,102 & 0.01 \\
\hline Bajureli & 10,704 & 0.04 & Pahari & 3,458 & 0.01 \\
\hline Darau & 11,677 & 0.04 & Sanskrit & 1,669 & 0.01 \\
\hline English & 2,045 & 0.01 & Khas & 1,747 & 0.01 \\
\hline \multicolumn{6}{|c|}{ 2. Sino-Tibetan (Tibeto-Burman) } \\
\hline Tamang & $1,353,311$ & 5.11 & Nepalbhasa & 846,557 & 3.19 \\
\hline Magar & 788,530 & 2.98 & Limbu & 343,603 & 1.297 \\
\hline Gurung & 325,622 & 1.23 & Bantaba & 132,583 & 0.50 \\
\hline Rai & 159,114 & 0.60 & Danuwar & 45,821 & 0.17 \\
\hline Chepang & 48,476 & 0.18 & Sunuwar & 37,898 & 0.14 \\
\hline Bhujel & 21,715 & 0.08 & Thami & 23,151 & 0.09 \\
\hline Thulung & 20,659 & 0.08 & Chamling & 76,800 & 0.29 \\
\hline Dhimal & 19,300 & 0.07 & Yakhka & 19,558 & 0.07 \\
\hline Khaling & 14,467 & 0.05 & Sangpang & 18,270 & 0.07 \\
\hline Bahing & 11,658 & 0.04 & Bambule & 13,470 & 0.05 \\
\hline Hyomlo & 10,176 & 0.04 & Nachiring & 10,041 & 0.04 \\
\hline Thmpu & 9,208 & 0.03 & Bote & 8,766 & 0.03 \\
\hline Ghale & 8,092 & 0.03 & Dumi & 7,638 & 0.03 \\
\hline Lepcha & 7,499 & 0.03 & Puma & 6,686 & 0.03 \\
\hline Jireli & 4,829 & 0.02 & Aathapaha- & 5,530 & 0.02 \\
\hline Meche & 4,375 & 0.02 & Thakali & 5,242 & 0.02 \\
\hline Raji & 3,758 & 0.01 & Mobahang & 4,650 & 0.02 \\
\hline Chhantyal & 4,283 & 0.02 & Tibbati & 4,445 & 0.02 \\
\hline Lohorung & 3,716 & 0.01 & & & \\
\hline \multicolumn{6}{|c|}{ 3. Austro-Asiatic (Munda } \\
\hline Santhali & 49,858 & 0.19 & Khadiya & 238 & 0.0008 \\
\hline \multicolumn{6}{|c|}{ 4. Dravidian } \\
\hline Uraue & 33,651 & 0.13 & Kisan & 1,178 & 0.004 \\
\hline \multicolumn{6}{|l|}{ 5. Others } \\
\hline Sanketik & 4,476 & 0.02 & Unknown & 68,891 & 0.26 \\
\hline
\end{tabular}

Source: Languages of Nepal, Wikipedia, retrieved 2019-3-26. 
Nepal is a multiple cultural country where around 125 languages are spoken as a mother tongue (first language) in Nepal. The statistics of major languages spoken in Nepal is as Nepali (44.6\%), Maithili (11.7\%), Bhojpuri (6.0\%), Tharu (5.8\%), Tamang (5.1\%), Newar (3.2\%), Bajjika (3.0\%), Magar (3.0\%), Doteli (3.0\%), and Urdu (2.6\%). Nepali is spoken by 44.64 percent in 2011 while it was 48 percent in 2001 (CBS, 2014). But each and every socio-cultural group has its own language which makes a spatial variation of linguistic geography in Nepal (Table 1).

Table 1 shows the toypologies of the verbal traditions of Nepalese languages which can be divided into four groups as Indo-Aryan, Sino-Tibetan or Tibeto-Burman, AustroAsiatic, and Dravidian. The overwhelmingly majority of people belonging to the Indo-Aryan (81.1\%) and Sino-Tibetan (17.3\%) language families while only a very few of them are Austro-Asiatic (0.2\%) and Dravidian (0.1\%). About 92 percent of the population who fall in Indo-Aryan language family resided in rural areas in 1991 which reduced to 87 percent in 2001. Similar trend also be observed for other language families (MoPE, 2017).

Spatial distribution of languages: Linguistic geography is considered to the study of regional distributions of languages and dialectics. Sounds, words, patterns, meaning and sentences are taken to determine language and their dialects in a particular geographical territory. The local people used different vocabularies, sentence patterns, phonemes and meanings of the same word. Omar \& Alotaibi (2017) viewed that when speakers of the same group are geographically apart, it is more likely that they use language differently due to the determining of isoglosses of a language. It is a major aspect of linguistic geography which signifies the semantics meaning of language which relates the social meaning of signals, their cognition and interpretation by receivers (Sant, 1982).

Actually, Nepali language is originated from the Sinja region of Karnali Pradesh about the $11^{\text {th }}$ century ago. Nowadays, Nepali language is widely spoken from the east to the west as well as north to the south and different parts of India, Bhutan and Myanmar. Maithili is a second largest language spoken mainly in the Tarai regions of Nepal, especially in the Dhanusha, Mahottori, Sarlahi, Siraha,Saptari, and Sunsari districts. Bhojpuri language is spoken in the central Tarai regions, particularly in Bara, Parsa, Nawalparasi, Rupandehi, Rautahat, Sarlahi, and Chitwan districts. Tharu language is widely spoken right from the eastern to the western Terai and the foothills of Kanchanpur, Kailali, Banke, Dang, Kapilbastu, Rupandehi, Nawalparasi, Chitwan, Bara, Rautahat, Sarlahi, Siraha, Saptari and Morang districts; with the significant variations in sounds, word patterns and meaning. 
Avadhi language is spoken in Kanchanpur, Kapilvastu, Rupandehi and Nawalparasi districts. It is seen from the historical heritage of 'Asoka Sthambh' (Pillar of Asoka) at Lumbini. Bajjika language is mostly spoken in Tarai and inner Tarai regions of Rautahat, Mahottari, and Sarlahi districts. Urduis commonly spoken in the Muslim dominated areas. In addition, Rajbanshi, Hindi, Danuwar, Kumal, Bote, Chureti, Koche, Meche, Dhimal English, Sanskrit etc. languages are also spoken in the different parts of Nepal. All these languages fall under the Bharopeli family. The figures indicate that Bharopeli family has covered wide geographical areas of Nepal.

In Nepal, ethic communities have also dialects in their own languages. Magar language is dominated in the hilly regions of Rolpa and Rukum districts while in Lamjung, Manang, and Kaski districts by Gurung language. The Manjh Kirant areas covered by Rai dialects and Limbu dialects in Ilam, Panchthar, Taplejung, Tehrathum, and Dhankuta districts. Similarly, Tamang is found in the periphery of Kathmandu valley including Rasuwa, Nuwakot, Sindhupalanchok, Makwanpur and Dhading, Kabhrepalanchok, and Dolakha districts.

It shows that each and every geographical area has dominated by a particular language family. The dispersion of different languages and their dialects correlated to the growth and development of linguistic diversity in Nepal.

Dialects of Nepali language: To analyze linguistic community and variables of dialects and sub-dialects of a particular language, specific geographical area is essential. Similarly, identifying the numbers of languages and dialects are spoken, compare and contrast the characteristics of similarities and differences, and comprehensibility of the dialects and sub-dialects of each language using its isoglosses are the main basis to analyze dialect variable or language. Because of isoglosses are supposed to the glosses for distinguishing languages and their dialects.

The number and area of language speakers are presented in a map after determining the number of speakers and their residential area consciously. Different indexes are set up and then presented in a linguistic map to represent the speakers of different languages. For example, Nepali language is spread from the east (Mechi) to the west (Mahakali) as well as from south to the north. However, the knowledge about the general patterns of distributions caste and ethnic groups considered in order to determine linguistic geography of Nepal. In this context, Gurung's study is more valuable for linguistic geography of Nepal. He mentioned that ethnic groups can be identified on the basis of their native homelands such as Kathmandu valley (Newar), Tarai and Inner Tarai (Tharu) and Kiranti groups (Rais and Limbus) in the eastern Nepal (2008). 
The Nepali language is also classified into various dialectic groups based on their geographical locations. They are classified into five broad groups, such as Purbeli (eastern), Majhhali (central), Orapachchhima (western), Majhapachchhima (midwestern) and Parpachchhima (far-western).

The eastern dialect spreads from Dailekh in the west to Jhapa in the east of Nepal and Assam of India and Burma (Myanmar). The ancient mythological documents (Veda) and (Upanishad) are also dialects in Nepali Language. In addition, the modern Nepali language is largely based on this dialectical standard. The speakers of Salyan, Rolpa, Rukum, Jajarkot and Dailekh of Karnali Pradesh often pronounced Da sound for Dha and Ra sound for Hra. Table 2 gives an example of Nepali and Khasani sub-dialects as follows.

Table 2: The standard sub-dialect of Nepali and Khasani groups /d/, /r/

\begin{tabular}{l|l|l|l|l|l|l}
\hline Standard Nepali & Bado & Chhoro & Padhaunu & Chadhaunu & Ke & Kamilo \\
\hline Khasani sub-dialect & Baro & Chhodo & Parhaunu & Charhaunu & Kya & Kimilo \\
\hline
\end{tabular}

Source: Lamsal, 2068.

Table 2 reveals the standard sub-dialect of Nepali and Khasani groups' /d/, /r/. The language used to the east of Dhaulagiri, Lumbini, and Gandaki areas is known as Parbati sub-dialectic family of Eastern dialect. The speakers of this dialect spoke the sound Chha for Cha in the standard of Nepali language (Table 3).

Table 3: The differences of Nepali and Parbati sub-dialect /ch/

\begin{tabular}{l|l|l|l}
\hline Standard Nepali & Janchha & Khanchha & Aaunchha \\
\hline Parbati sub-dialect & Jancha & Khancha & Aauncha \\
\hline
\end{tabular}

Source: Lamsal, 2068 .

The Eastern dialect spoken from the east of Gorkha to Jhapa districts is known as Gorkhali sub-dialect. Table 4 reveals some of the examples of Gorkhali sub-dialect.

Table 4: The differences between the standard of Nepali and Gorkhali sub-dialect

\begin{tabular}{l|l|l|l|l|l|l|l}
\hline Standard Nepali & Bhainsi & Bhaini & Man & Chhaina & Rahechhan & Uniharu & Hamiharu \\
\hline Gorkhali sub-dialect & Bhuinsi & Buini & Mun & Chhuina & Raan & Undaru & Hameru \\
\hline
\end{tabular}

Source: Lamsal, 2068. 
The Majhhali dialect of Nepali language is widely practiced in the west of the Karnali River especially in northern Humla, Dolpa, upper part of Mahakali and Bheri zones. Table 5 shows the differentiation of pronunciation among the Majhhali dialects with Nepali standard.

Table 5: The differentiation of pronunciation of Majhhali dialects and Nepali standard

\begin{tabular}{c|l|l|l|l}
\hline Standard Nepali & Chari & Gara & Jahan & Badal \\
\hline Majhhali dialect & Chadi & Gada & Jhhan & Bald \\
\hline
\end{tabular}

Source: Lamsal, 2068.

The Orapachchhima dialect of Nepali language is spoken in the area of Bajhang, Bajura and Achham districts. Table 6 gives some of the examples of Orapachchhima dialect.

Table 6: The standard of Nepali and Orapaschhima dialects

\begin{tabular}{l|l|l|l|l|l}
\hline Standard Nepali & Yiniharu & Janchhu & Thiyo & Swasnimanchhe & Garnu \\
\hline Orapachchhima dialect & In & Jhhano & Chyo & Swainimanis & Hannu \\
\hline
\end{tabular}

Source: Lamsal, 2068 .

The dialect spoken in the area of Doti and Dadeldhura district is known Majhapachchhima dialect. While the dialect spoken in the areas of Baitadi, Duhuha, Marmaa, Laykam, Chuhagadh, Puchaudi of Mahakali Zone is known as Parapachimma dialect. The paper reveals that the government of Nepal has recognized a separate identity for the dialects spoken in the far western region in the census year of 2011. It represents a correlation between the dialects and standard of Nepali language in terms of their structure of language and grammatical rules. As a result these dialects cannot be discarded from the mainstreaming of Nepali languages (Table 6).

Table 6: Differences in pronouncing words in standard Nepali and Parapaschhima dialect

\begin{tabular}{l|l|l|l|l}
\hline Standard Nepali & Parchha & Thutuno & Aama & Dewar \\
\hline Parapachimma dialect & Padanchha & Jamyalo & Ija & Gosi \\
\hline
\end{tabular}

Source: Lamsal, 2068.

The above discussion revealed that various dialect and sub-dialectic families of the Nepali languages are widely practiced in different geographical parts of Nepal. Nepali language has covered a wide range of diversity regarding both geographic and cultural areas. However, their number and frequencies are varied to the use of each and every 
language family in various ways. The language spoken in a specific geographical area makes diversity in language due to its geographical location as language geology.

\section{Conclusion}

The comprehensive study of Nepalese linguistic geography shows many different dialects and variations of language in different part of the country. Geographical diversities in the country gave the birth of dialects and the dialects also have some diversity. All languages practiced so far in Nepal have their own geographical territory and spatial value. They have their own socio-cultural, linguistic and historical contexts. The geographic environment of Rai and Limbu, and Magar and Gurung are different's. There is no comprehensibility in the varieties of Nepali language used in Taplejung and the way is used in Darchula. The discipline of studying the differences in the languages spoken in one area form another area has to be promoted. Investigation on the diversities, differences and the number of each language in terms of their regional basis is the geography of language in a true sense is linguistic geography.

\section{References}

Abdulfattah, O. \& Mansour, A. (2017) . Geographic location and linguistic diversity: The use of intensifiers in Egyptian and Saudi Arabic. www.researchgetnet. 2019-3-24.

Central Bureau of Statistics (CBS). (2014). Population monograph of Nepal. Kathmandu: CBS.

Dhungel, B.R. (2009). Linguistic geography: An introduction. Sampreshan. Kirtipur: Department of Nepali Education, FOE, TU..

Gautam, D.P. (2049). Nepali Bhasha Parichaya. Kathmandu: Sajha Prakashan.

Gold, J. R. (1980). An introduction to behavioral geography. New York: Oxford University Press.

Gregory, D., Johnston, R., Pratt, G., Watts, M.J. \& Whatmore, S. (2009). The Dictionary of Human Geography. Wiley-Blackwell.

Gurung, H. (1989). Nature and culture: random reflections. Kathmandu: Mrs. Saroj Gurung.

Gurung,H.(2008). Bahiskarandekhisamabesikaransamma. Nepalkalagisamajikrajnitikajenda. Kathmandu: Samajik Samabesi Kosha.

Khanal, M.P. (2068). Nepali bhasha ka hajarvarsha. Kathmandu: Raino Publication. 
Lamsal, R. (2068). Nepali bhasha ra byakaran. Kathmandu: Sunlight Publication.

Lippuner, R. \& Werlen, B. (2009). Structuration Theory. Elsevier Ltd.

Ministry of Population and Environment (MoPE). (2017). National population report 2017. Kathmandu: MoPE.

Neupane, T. P., Bhandari, P. M., Neupane, D. \& Ghimere, T. R. (2069), Samanyabhashavigyan. Kathmandu : Sunlight Publication.

Pokhrel, B.K. (2050). Pancha Sayavarsha. Kathmandu: Sajha Prakashan.

Sant, M. (1982), Applied geography: Practice, problems and prospects. London: Longman.

Smith, R.G. (2009). Structuralism geography. In International Encyclopedia for Human Geography. Elsevier

Tiwari, B.N. (2005). Linguistics. Illahabad: Kitab Mahal.

Werlen, R. (2009). Everyday regionalisation. In International Encyclopedia for Human Geography. Elsevier.

Withers, C. (2011). Language. In Gregory, D. et al. (Eds.) The Dictionary of Human Geography. Wiley-Blackwell. 